\title{
Age-hardening of Ti-35Nb-7Zr-5Ta Alloy for Orthopaedic Implants
}

\author{
Elisa Bueno Taddei ${ }^{a *}$, Vinicius Andre Rodrigues Henriques ${ }^{\mathrm{b}}$, \\ Cosme Roberto Moreira da Silva ${ }^{\mathrm{a}}$, Carlos Alberto Alves Cairo ${ }^{\mathrm{b}}$ \\ anstituto Tecnológico de Aeronáutica - ITA/CTA, 12228-900 São José dos Campos - SP, Brazil \\ bAMR, Divisão de Materiais, IAE/CTA, São José dos Campos - SP, Brazil
}

Received: March 15, 2007; Revised: June 19, 2007

\begin{abstract}
Bone injuries and failures often require the inception of implant biomaterial. Research in this field has received increasing attention recently. In particular, porous metals are attractive due to its unique physical, mechanical, and new bone tissue ingrowth properties. The aim of this work is to investigate age hardening behavior of Ti-35Nb$7 \mathrm{Zr}-5 \mathrm{Ta}$ alloy produced by powder metallurgy. Samples of Ti-35Nb-7Zr-5Ta were produced from a mixture of hydrided powders followed by uniaxial and cold isostatic pressing with subsequent densification by sintering at $1500{ }^{\circ} \mathrm{C}$, in vacuum. After that, the samples were heat treated in three steps; solution treatment $\left(1100{ }^{\circ} \mathrm{C}\right)$, air cooling and aging $\left(600^{\circ} \mathrm{C}\right.$ for 4 and 6 hours). Sintered samples were characterized for microstructure and microhardness by scanning electron microscopy and Vickers indentation, respectively. In the homogenized condition alloy exhibited a microstructure consisting primarily of a $\beta$ Ti matrix with grain boundary $\alpha$ precipitates and a low volume fraction of primary $\alpha$ precipitates. In the ageing condition the alloy exhibited the precipitation of refined scale secondary $\alpha$ precipitates distributed homogeneously in the $\beta$ matrix.
\end{abstract}

Keywords: Age-hardening, Ti-35-Nb-7Zr-5Ta, biomaterial, powder metallurgy

\section{Introduction}

Powder metallurgy has proved to be an attractive technique for processing titanium surgical implants due to the low sintering temperatures and the possibility of obtaining porous controlled structures which allow bone ingrowth. Porous surface implants have been successfully used to improve the bone-implant interfacial resistance and provide a more efficient fixation of the implant. These implants have shown to enhance the implant osseointegration due to the higher specific surface in contact with bone when compared with smooth titanium implants ${ }^{1}$.

Porosity characterization is considered essential for porous surfaced implants because the pore size and pore morphology influence cellular adhesion. An increase in the fraction of open porosity is required, because it improves implant to bone fixation by the growing of bone-forming tissues inside de pores ${ }^{2}$.

Powder Metallurgy (P/M), also referred to as sintering, is a highly developed method of manufacturing reliable ferrous and nonferrous parts. Made by mixing elemental or alloy powders and compacting the mixture in a die, the resultant shapes are then sintered or heated in a controlled-atmosphere furnace to bond the particles by metallurgical process. $\mathrm{P} / \mathrm{M}$ is essentially a forming process. The part does not always emerge ready for use at the end of the sintering step even though it has acquired a certain level of mechanical properties. Just as with alternative technologies it is possible to modify some of these properties, to improve the shape or the dimensional accuracy so as to extend the range of application ${ }^{3}$.

Since the $\beta$ phase in Ti alloys exhibits a significantly lower modulus than the $\alpha$ phase, and the $\beta$ alloys also satisfy most of the other requirements for an ideal bioalloy, there is a thrust towards the development of lower modulus $\beta$-Ti alloys which retain a single $\beta$ phase microstructure on rapidly cooling from high temperatures. Biomedical alloys have widespread application in joint replacement and other orthopaedic surgeries. While the primary properties of inter- est with respect to biomedical alloys are biocompatibility, corrosion resistance and wear resistance, it is the lack of their load-bearing capability that limits their applicability. The newer biomedical alloys, exhibit relatively low modulus while maintaining sufficient strength and contain alloying additions that are completely biocompatible ${ }^{4}$. In special, Ti-35Nb-7Zr-5Ta alloy (TNZT), which has a low modulus of elasticity ( $55 \mathrm{GPa}$ ), can be considered as the best one material to be used as a orthopaedic implant. In addition, this alloy is composed of non-toxic and non-allergic elements with excellent mechanical properties and workability ${ }^{5-7}$.

Depending upon the thermomechanical treatment and alloying elements of metastable $\beta$ Ti alloys, various phases and morphology result. The high temperature allotropic phase of titanium is retained upon quenching given the presence of sufficient levels of stabilizer elements and its crystal structure is bcc. Solution treating and annealing precipitation of alpha phase, omega phase and or intermetallics improves yield strength and fracture toughness. The morphology, size and distribution, of these precipitates determine in large part the mechanical properties of the alloy ${ }^{8}$.

Decomposition of $\beta$ solution treated and rapidly cooled $\mathrm{Ti}-\mathrm{Nb}$ alloys upon subsequent aging may additionally occur either by direct precipitation of the stable $\beta$ phase, or may involve a two step process wherein the first stage includes formation of another metastable phase, hcp omega phase, subsequent aging for longer times resulting in precipitation of $\alpha^{9}$.

The aim of this work is to investigate age hardening behavior of Ti35Nb-7Zr-5Ta alloy produced by powder metallurgy.

\section{Materials and Methods}

The blended elemental method followed by a sequence of uniaxial and cold isostatic pressing with subsequent densification by sintering was chosen for the preparation of the alloy. 
All the powders were obtained by hydriding method and sintered in hydrided state. The starting powders were weighed $(30 \mathrm{~g})$ and dried for one hour in stove and blended for 30 minutes in a planetary mill with six drips of alcohol. After blending, the powders were cold uniaxially pressed under pressure of $60 \mathrm{MPa}$, in cylindrical $15 \mathrm{~mm}$ dia.-dies. Afterwards, samples were encapsulated under vacuum in flexible rubber molds and cold isostatically pressed (CIP) at $350 \mathrm{MPa}$ during 30 seconds in an isostatic press.

Sintering was carried out in niobium crucible in high vacuum condition $\left(10^{-7}\right.$ Torr $)$, at $1500{ }^{\circ} \mathrm{C}$, in vacuum. After that, the samples were heat treated in three conditions; solution treatment $\left(1100{ }^{\circ} \mathrm{C}\right)$, air cooling and aging $\left(600{ }^{\circ} \mathrm{C}\right.$ for 4 and 6 hours). Metallographic preparation was carried out using conventional techniques. Specimens were etched with a Kroll solution: $1.5 \mathrm{~mL} \mathrm{HF:} 2.5 \mathrm{~mL} \mathrm{HNO}_{3}$ : $100 \mathrm{~mL} \mathrm{H}_{2} \mathrm{O}$, for 50 seconds, to reveal its microstructure. Microhardness measurements were carried out in a Micromet 2004 equipment (Buehler) with a load of $0.2 \mathrm{kgf}$ (15 indentations). The micrographs were obtained using a SEM LEO model 435VPi.

\section{Results and Discussion}

The samples sintered at $1500{ }^{\circ} \mathrm{C}$ (Figure 1a) presented the best results when compared to the microstructure found in commercial parts, with a $\beta$-homogeneous microstructure and with low porosity. Due the complete dissolution of the alloys elements in the titanium matrix, a good combination of microstructure, mechanical properties and densification could be reached. The sample presented microhardness values around $350 \mathrm{HV}$, next to the observed in samples produced by the conventional methods (melting) ${ }^{10}$.

The microstructure of the TNZT alloy in the solution treated condition is shown in the Figure 1b. The microstructure consists of relatively large grains of the phase $\beta$ with grain boundary $\alpha$ precipitates. In addition, some amount of intra-granular $\alpha$ precipitation is also visible within the $\beta$ grains. These intra-granular primary $\alpha$ precipitates often exhibit rather different morphologies (plates and needles). The average microhardness of the TNZT alloy in the homogenized condition is $479 \mathrm{HV}$.

The Figure 2 shows the $\alpha$ and $\beta$ areas (homogenized at $1100{ }^{\circ} \mathrm{C}$ ) where the analyses for EDS were carried out. Table 1 presents the result of the quantitative analysis of the elements. Areas 1 and 2 are preferentially, $\beta$ and $\alpha$ regions, respectively, and the EDS analyses represent the compositions of these phases in the alloy. The Table 1 shows that the niobium presents a superior content in $\beta$-phase, due to its power of preferential stabilization of this phase.

The microstructure of the TNZT alloy after ageing at $600{ }^{\circ} \mathrm{C}$ for 4 and 6 hours are shown in Figures $3 \mathrm{a}$ and b, respectively. An increased volume fraction of the intra-granular primary $\alpha$ precipitates is visible in these figures as compared to Figure 1b. The values of microhardness of the homogenized TNZT alloy after ageing for 4 and 6 hours are 356 and $326 \mathrm{HV}$ respectively. In addition to the coarser intra-granular $\alpha$ precipitates, a finer scale secondary $\alpha$ precipitation occurs after the ageing treatment. These precipitates are homogeneously distributed throughout the $\beta$ matrix. Moreover, it can be noted that there are some precipitate free zones surrounding the grain boundaries.

The reduction in the microhardness and consequently the strength of the TNZT alloy after ageing is rather surprising, since the homogeneous precipitation of the fine scale $\alpha$ after ageing is expected to increase the strength of the alloy. However, similar behavior has been also observed during heat treatment of TNZT samples produced by ingot metallurgy ${ }^{11}$.

The Figure 4 shows the $\alpha$ and $\beta$ areas (solution treated and aged at $600{ }^{\circ} \mathrm{C}$ for 4 hours) where the analyses for EDS were carried out. Table 2 presents the result of the quantitative analysis of the elements.
The Table 2 shows that the niobium presents a superior content in $\beta$-phase as indicated in the solution treated sample.

The porous presence is an important feature for osteointegration, aiming surgical implants application, where a high porosity is necessary. An efficient route to control the pore content in TNZT samples is selecting an adequate space holder. This sintering method in order

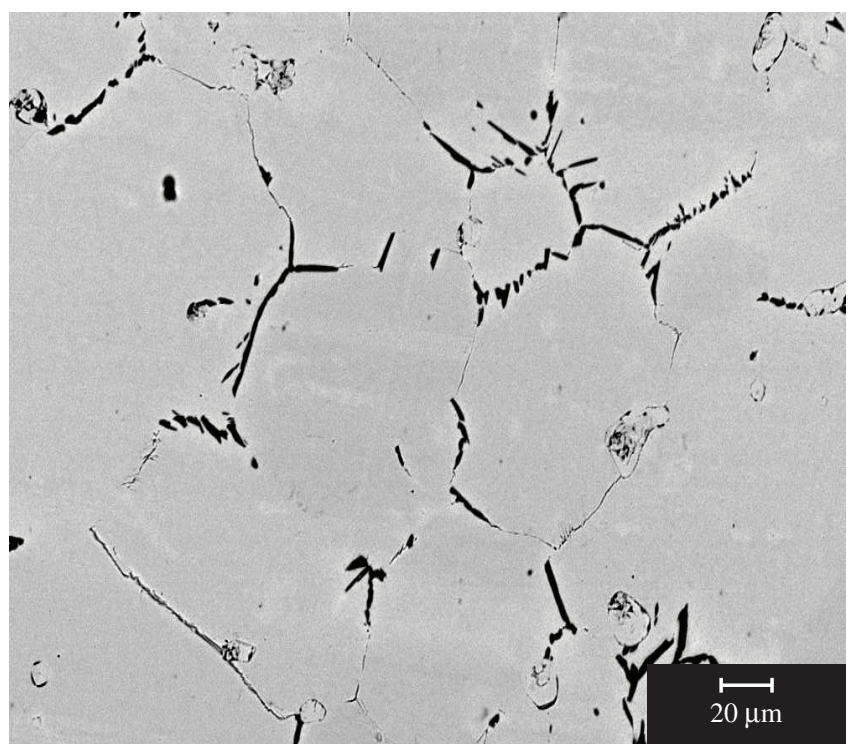

(a)

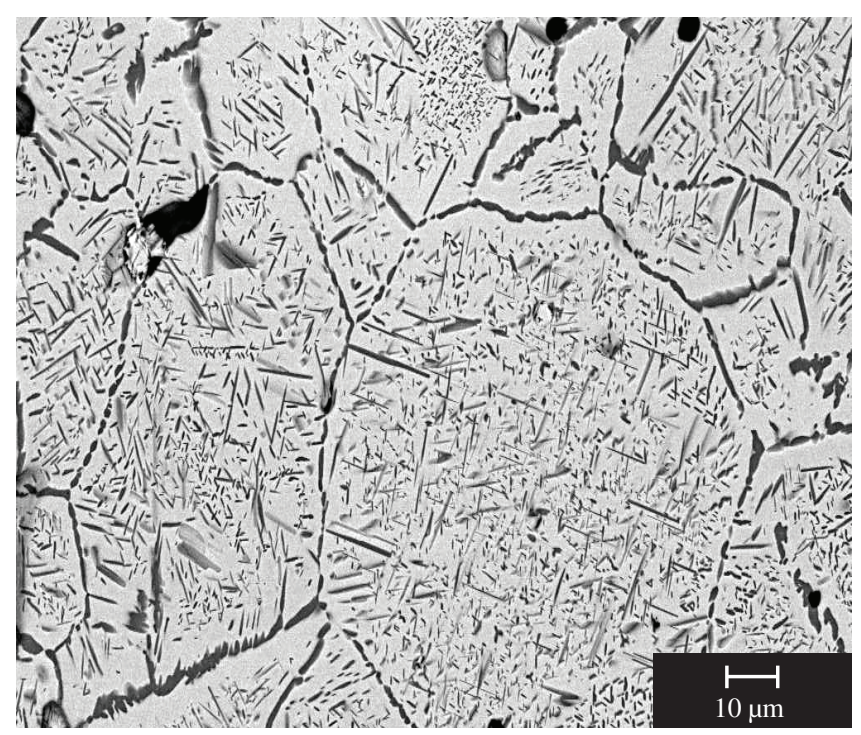

(b)

Figure 1. SEM images of the microsctructure TNZT sample. a) Ti-35Nb-7Zr5Ta sintered at $1500{ }^{\circ} \mathrm{C}$; and b) Homogenized TNZT sample.

Table 1. Ti, Nb, Zr and Ta contents in the areas analyzed (EDS).

\begin{tabular}{ccccc}
\hline \multirow{2}{*}{ Site } & \multicolumn{4}{c}{ Composition (wt. (\%)) } \\
\cline { 2 - 5 } & $\mathrm{Ti}$ & $\mathrm{Nb}$ & $\mathrm{Zr}$ & $\mathrm{Ta}$ \\
\hline$(1)$ & 56.64 & 34.58 & 2.10 & 6.79 \\
$(2)$ & 81.74 & 10.90 & 1.16 & 6.21 \\
$(3)$ & 76.06 & 16.53 & 1.55 & 6.22 \\
\hline
\end{tabular}




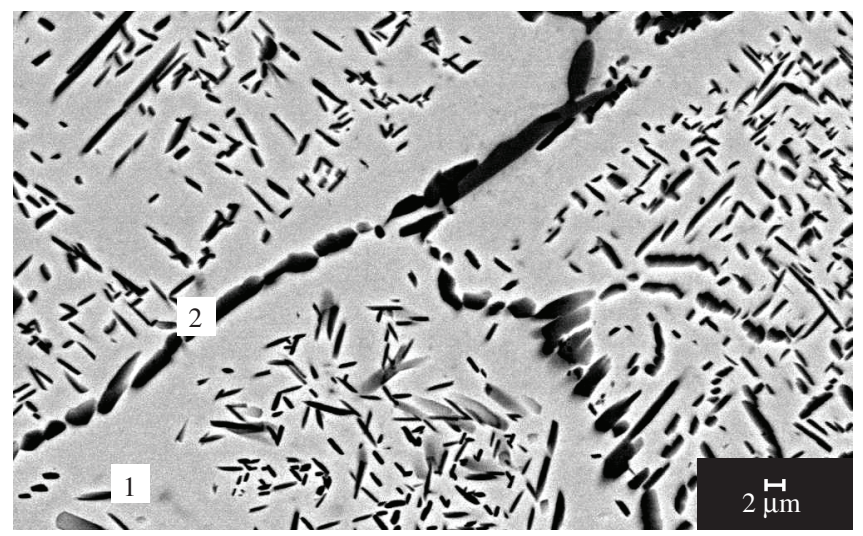

Figure 2. $\beta$-phase (1), $\alpha$-phase (2) areas analyzed for EDS in Ti-35NB$7 \mathrm{Zr}-5 \mathrm{Ta}$.

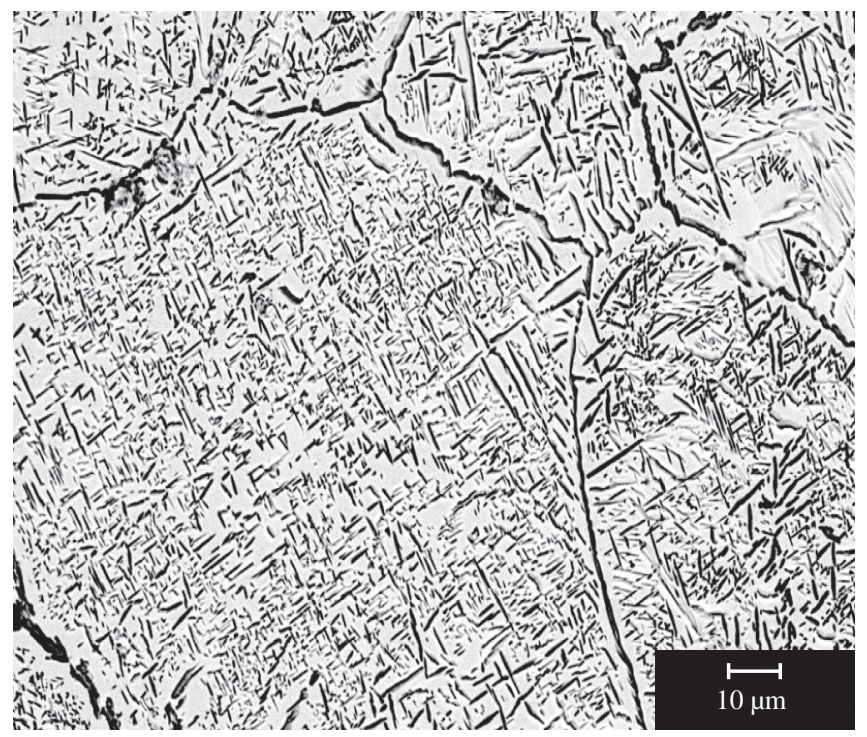

(a)

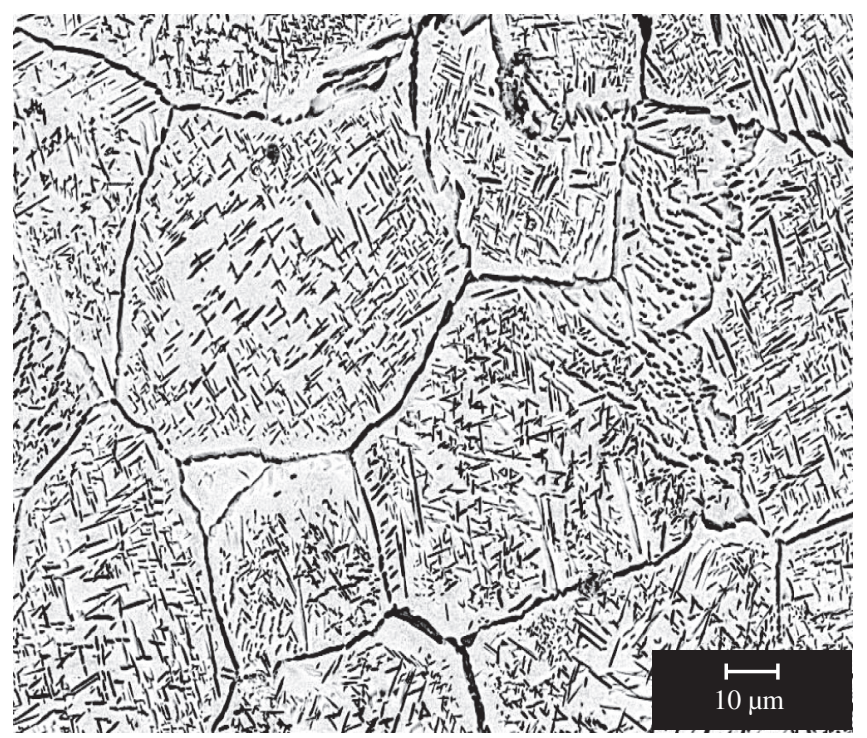

(b)

Figure 3. SEM images of the aged TNZT sample. a) Aged at $600{ }^{\circ} \mathrm{C}$ for 4 hours; and b) Aged at $600{ }^{\circ} \mathrm{C}$ for 6 hours.

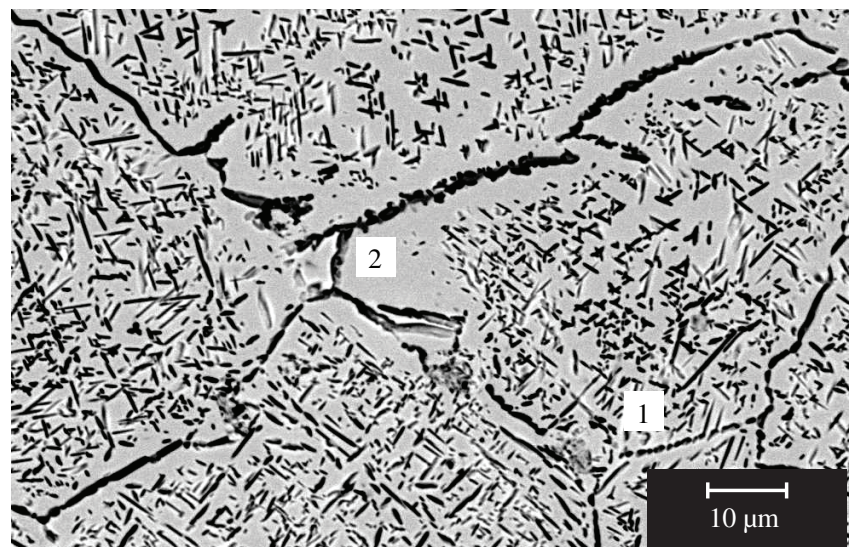

Figure 4. $\alpha$-phase (1) and $\beta$-phase (2) areas analyzed for EDS in Ti-35NB7Zr-5Ta.

Table 2. $\mathrm{Ti}, \mathrm{Nb}, \mathrm{Zr}$ and $\mathrm{Ta}$ contents in the areas analyzed (EDS).

\begin{tabular}{ccccc}
\hline \multirow{2}{*}{ Site } & \multicolumn{5}{c}{ Composition (wt. \%) } \\
\cline { 2 - 5 } & $\mathrm{Ti}$ & $\mathrm{Nb}$ & $\mathrm{Zr}$ & $\mathrm{Ta}$ \\
\hline$(1)$ & 56.45 & 34.59 & 7.09 & 1.87 \\
$(2)$ & 44.32 & 45.72 & 7.63 & 2.33 \\
\hline
\end{tabular}

to manufacture highly porous metallic materials, was investigated by the authors and its results will be describe in a further paper.

\section{Conclusions}

The results of the microstructural analyses in Ti-35Nb-7Zr-5Ta samples produced by $\mathrm{P} / \mathrm{M}$ show that a $\beta$-homogeneous microstructure is obtained in the whole sample extension with the increase of the sintering temperature and the dissolution of $\mathrm{Nb}$ particles. The sintering parameters provided a homogeneous microstructure, with low porosity and contamination. In the solution treated condition, alloy exhibited a microstructure consisting primarily of a $\beta$ Ti matrix with grain boundary $\alpha$ precipitates and a low volume fraction of primary $\alpha$ precipitates. In the ageing condition the alloy exhibited the precipitation of refined scale secondary $\alpha$ precipitates distributed homogeneously in the $\beta$ matrix. The microhardness results seems to suggest (if there was not oxidation during the heat treatment) that a metastable ordering in the matrix of the solution treated TNZT alloy results in increased values of hardness for this alloy. On ageing, the precipitation of fine-scale secondary $\alpha$ probably destroys the ordering in the matrix, leading to the sample softening. Therefore, further detailed investigations of the microstructural evolution in this alloy were carried out using transmission electron microscopy (TEM).

\section{Acknowledgments}

The authors wish to thank FAPESP for the scholarship of Taddei, E. B. and the Materials Department of Escola de Engenharia de Lorena - USP Lorena for the $\mathrm{Nb}$ and Ta supplying.

\section{References}

1. Medeiros WS, Oliveira MV, Pereira LC, Cairo CAA, Calixto MA. Calcium Phosphate Deposition on Porous Titanium Samples. In Fifth International Latin-American Conference on Powder Technology, 2005, Costa do Sauipe. Procedings of Fifth International Latin-American Conference on Powder Technology; 2005; Metallum Eventos Técnicos Científicos, 2005. Bahia, Brazil, v. CD. 
2. Oliveira MV, Moreira AC, Appoloni CR, Lopes RT, Pereira LC, Cairo, CAA. Porosity Study of Sintered Titanium Foams. In Fifth International Latin-American Conference on Powder Technology, 2005, Costa do Sauipe. Procedings of Fifth International Latin-American Conference on Powder Technology; Metallum Eventos Técnicos Científicos, 2005. Bahia, Brazil.

3. Ierardi MCF, Siviero Filho CA, Figueira Filho DTA. Electroplating of Strutural P/M Parts - Medium Density Steel Parts. In Fifth International Latin-American Conference on Powder Technology, 2005, Costa do Sauipe. Procedings of Fifth International Latin-American Conference on Powder Technology; Metallum Eventos Técnicos Científicos, 2005. Bahia, Brazil.

4. Banerjee R, Nag S, Fraser H. A novel combinatorial approach to the development of beta titanium alloys for orthopaedic implants. Materials Science and Engineering C. 2005; 25:282-289.

5. Niinomi, M. Fatigue performance and cytotoxicity of low rigidity titanium alloy, Ti-29Nb-13Ta-4.6Zr. Biomaterials. 2003; 24(16):2673-2683.
6. Katti KS. Biomaterials in total joint replacement, Colloids and Surfaces B. Biointerfaces. 2004; 39(3):133-142.

7. Geetha M, Kamachi Mudali U, Gogia AK, Asokamani R, Raj B. Influence of microstructure and alloying elements on corrosion behavior of Ti-13Nb-13Zr alloy. Corrosion Science. 2004; 46(4):877-892.

8. Ankem CA. Greene, Recent developments in microstructure:property relationships of beta titanium alloys. Materials Science and Engineering A. 1999; 263(2):127-131.

9. Qazi JI, Marquardt B, Allard LF, Rack HJ. Phase transformations in Ti35Nb-7Zr-5Ta- (0.06-0.68) O alloys. Materials Science and Engineering C. 2005; 25(3):389-397.

10. Allvac, An Allegheny Technologies Company, Catalogue.

11. Banerjee R, Nag S, Stechschulte J, Fraser HL. Strengthening mechanisms in Ti-Nb-Zr-Ta and Ti-Mo-Zr-Fe orthopaedic alloys. Biomaterials. 2004; 25(17):3413-3419. 